\title{
Age-specific seroprevalence of hepatitis A in Sari, northern Islamic Republic of Iran
}

\author{
S. Alian, ${ }^{1}$ A. Ajami, ${ }^{2}$ R. Ghasemian ${ }^{\text {and D. Yadegarinia }}{ }^{3}$
}

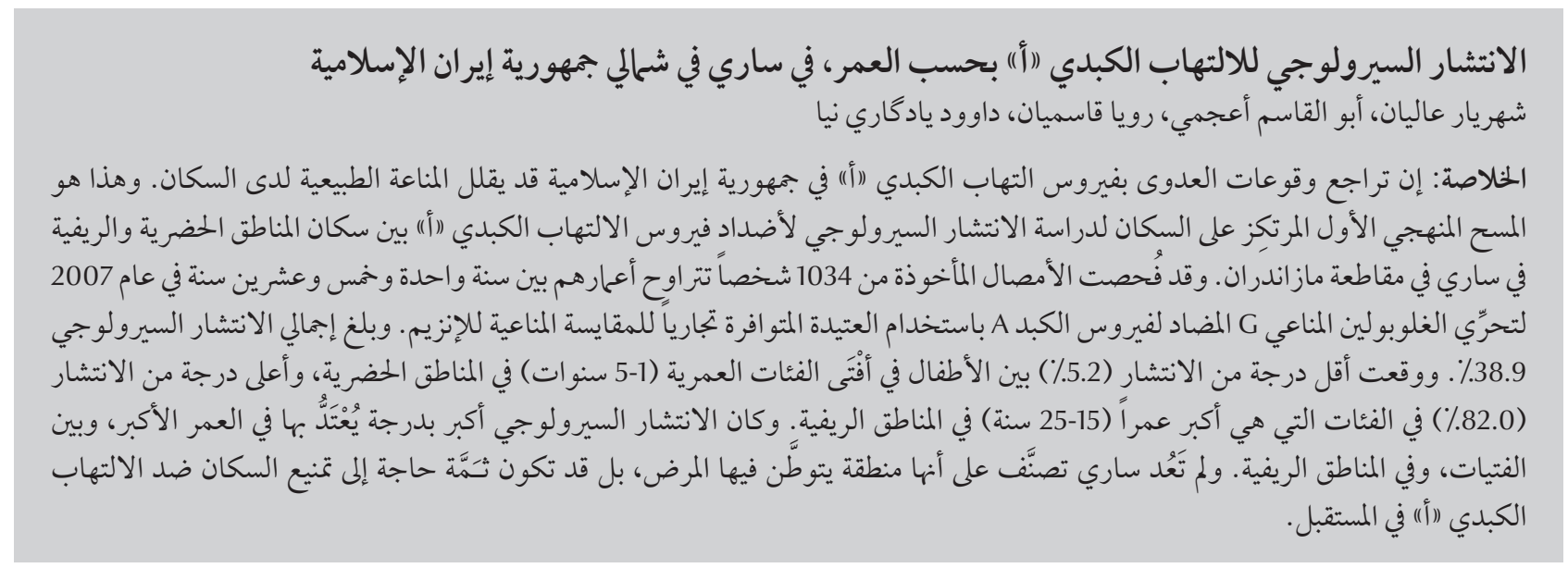

ABSTRACT The declining incidence of hepatitis A virus (HAV) infection in the Islamic Republic of Iran may be reducing the population's natural immunity. This was the first systemized, population-based survey of the seroprevalence of HAV antibodies in urban and rural inhabitants of Sari, Mazandaran province. Serum from 1034 individuals aged 1-25 years in 2007 were tested for anti-HAV IgG antibody using a commercial enzyme immunoassay kit. The overall seroprevalence was 38.9\%. The lowest prevalence (5.2\%) was among the younger age group (1-5 years) from urban areas and the highest prevalence (82.0\%) in the older age group (15-25 years) from rural areas. Seropositivity was significantly higher at higher age, among females and in rural areas. Sari is no longer classified as an area of high endemicity, and immunization against HAV may be needed in our population in the future.

\section{Séroprévalence de l'hépatite A en fonction de l'âge à Sari (nord de la République islamique d'Iran)}

RÉSUMÉ La baisse de l'incidence de l'infection par le virus de l'hépatite A en République islamique d'Iran pourrait être en train d'affaiblir l'immunité naturelle de la population. Il s'agit de la première enquête systématique en population sur la séroprévalence des anticorps du virus de l'hépatite A chez les habitants des zones urbaines et rurales de Sari, dans la province de Mazandaran. Un échantillon de sérum prélevé chez 1034 personnes âgées d'un an à 25 ans en 2007 a été analysé à la recherche d'anticorps IgG du virus de l'hépatite A à l'aide d'une trousse commerciale pour épreuve immuno-enzymatique. La séroprévalence globale était de 38,9 \%. La prévalence la plus faible (5,2\%) a été observée dans la tranche d'âge la plus jeune (1 à 5 ans) dans les zones urbaines et la prévalence la plus élevée (82,0 \%) dans la tranche d'âge la plus âgée (15 à 25 ans) dans les zones rurales. La séropositivité était significativement plus élevée à un âge plus avancé, chez les femmes et dans les zones rurales. Sari n'est plus classée comme une zone à forte endémicité, et la vaccination contre le virus de I'hépatite A pourrait s'avérer nécessaire dans notre population à l'avenir.

${ }^{7}$ Department of Infectious Diseases; ${ }^{2}$ Department of Immunology, Mazandaran University of Medical Sciences, Sari, Islamic Republic of Iran (Correspondence to R. Ghasemian: roya37gh@yahoo.com).

${ }^{3}$ Infectious Diseases and Tropical Medicine Research Centre, Shahid Beheshti University ofMedical Sciences, Tehran, Islamic Republic of Iran. Received: 06/01/10; accepted: 08/03/10 


\section{Introduction}

Hepatitis Avirus (HAV) is an epidemiologically important virus, responsible for about 1.4 million new infections worldwide each year. Most HAV infections occur through fecal-oral transmission, either by direct contact with an infected person or by ingestion of contaminated food or water [1]. Low socioeconomic status, high density housing and inadequate water treatment contribute to a pattern of high endemicity in developing countries in which more than $90 \%$ of the population has acquired natural immunity before the age of 10 years often from an asymptomatic infection.

The epidemiological pattern of HAV infection is currently changing in many developing countries, where improved sanitary conditions, urbanization and hygiene practices have reduced the incidence of infection [2]. This decrease in the infection rate has a paradoxical effect. As socioeconomic conditions improve, individuals become infected at a later age when the disease is more severe. HAV infection in children is often asymptomatic, whereas most infected adults present with jaundice and other potentially severe symptoms. Thus, HAV morbidity may increase as the incidence of infection decreases [3].

Because infection with HAV generally confers lifelong immunity to all strains of HAV, age-specific seroprevalence rates are indicators of the level of susceptibility to severe disease in a population. The epidemiology of HAV in any sub-group of the Iranian population is not properly known due to the lack of seroprevalence studies. HAV is an endemic infection in our country, so there has been no need for prevention until recent years. However, reports of a growing number of cases of fulminant hepatitis $\mathrm{A}$ in our region during recent years are prompting a debate over whether or not the Islamic Republic of Iran is experiencing an epidemiology shift in HAV infection.
This study in 2007 examined the seroprevalence of hepatitis A in Sari city and surroundings. The aims of this study were to determine the age-specific seroprevalence of HAV in a young population (between 1 and 25 years) in urban and rural areas. It was hoped that the results would provide useful epidemiological information on which to plan HAV prevention efforts.

\section{Methods}

\section{Study design and population}

This was a descriptive study of HAV seroprevalence in individuals aged between 1 and 25 years from Sari during May and September 2007.

Sari is the capital of Mazandaran provincelocated on the south side of the Caspian sea in the north of the Islamic Republic of Iran. Sari city consists of administrative, commercial, industrial and residential areas, with large areas of agricultural land that are mostly rice fields.

Multistage random sampling was used. According to previous data [4] with $80 \%$ estimated seroprevalence at 95\% confidence level, the calculated sample size was 1034 people. According to the population distribution we took $60 \%$ of samples from the town and $40 \%$ from the rural areas of Sari. After division of Sari city into 4 geographical regions, we selected 2 health care centres in each region. In the next step we choose our samples randomly from family files in each health centres (78 cases in each part). For sample recruitment we invited the selected people to health centres and for children we used schools and kindergarten in every region. In the rural areas we choose 6 villages randomly in the north, south and east of Sari. In every selected village we choose our samples randomly (based on random number tables) from rural health centres.

Informed, written consent was obtained from the participants or the parents of children. The study was approved by the ethics committee of Mazandaran University of Medical Sciences.

\section{Data collection}

A total of 1034 blood samples (620 and 414 from urban and rural areas respectively), were collected during May to September 2007 from people aged between 1 and 25 years. Serum samples were tested for IgG antibodies to HAV using a qualitative enzyme immunoassay kit (anti-HAV IgG EIA, Dia.Pro Diagnostic Bioprobes srl). Results were read on a multimode plate reader and were compared with the optical densities of positive and negative controls.

Epidemiological data were collected from questionnaires and included general information about the target population (age, sex, type of residence and water supply).

\section{Statistical analysis}

All data were statistically assessed by the chi-squared and Fisher exact test, using SPSS software, version 10. $P<0.05$ was accepted as the level of significance.

\section{Results}

\section{Study population}

Anti-HAV antibody status was studied in all 1034 subjects enrolled. There were 192 subjects aged $1-5$ years, 330 aged $5-15$ years and 512 aged $15-25$ years (Table 1). Of the 1034 serum samples analysed for the anti-HAV (IgG) antibody, 620 samples were from urban and 414 from rural areas in Sari.

The overall prevalence of anti-HAV antibody was $38.9 \%(402 / 1034)$. Table 1 shows the age-specific prevalence of anti-HAV antibodies $(\operatorname{IgG})$ in the population studied. Only $13.8 \%$ of subjects under 15 years old had immunity against HAV. The lowest prevalence (5.2\%) was in the younger age group (1-5 years) from the urban area and the highest prevalence $(82.0 \%)$ in the 


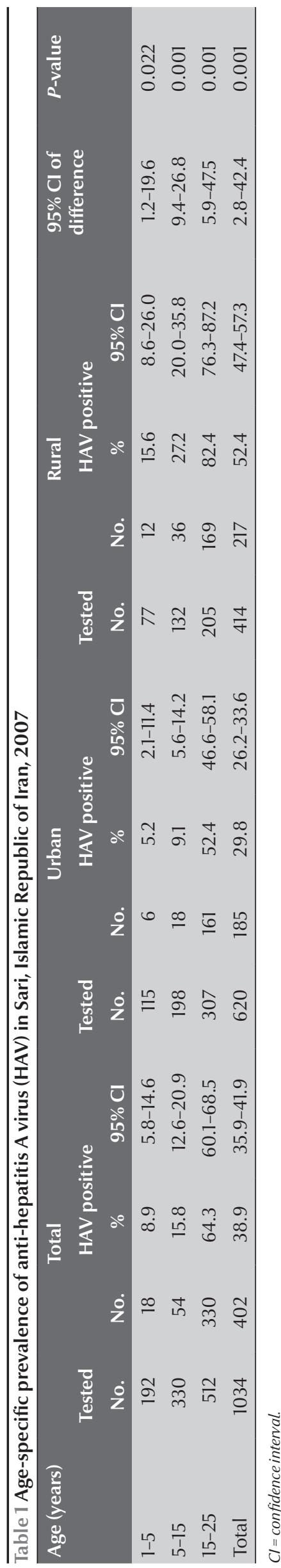

older age group ( $15-25$ years) from the rural area. Anti-HAV seropositivity increased significantly with increasing age, independent of area of residence $(\mathrm{OR}=$ $1.89,95 \% \mathrm{CI}: 1.07-3.30$ for age group $5-15$ years and $\mathrm{OR}=17.5,95 \% \mathrm{CI}$ : 10.4-29.4 for age group 15-25 years) $(P<0.001)($ Table 2$)$.

The overall rate of anti-HAV seropositivity was significantly higher in the samples from rural than urban areas $(52.4 \%$ versus $29.8 \%)(P<0.018)(\mathrm{Ta}-$ ble 2) $(\mathrm{OR}=1.39,95 \% \mathrm{CI}: 1.06-1.83)$. The same pattern of urban/rural differences was found in each age group (data not shown).

Overall, there was a significant difference in the probability of being antiHAV seropositive between females and males $(46.0 \%$ versus $29.6 \%)(\mathrm{OR}=2.02$, 95\% CI: 1.50-2.60) $(P=0.16)$ (Table $2)$. This difference was not significant in urban areas [35.9\% $(147 / 410)$ in females versus $28.6 \%(60 / 210)$ in males] $(P=0.072)$ but was significant in rural areas $[73.5 \%(194 / 264)$ in females versus $15.3 \%(23 / 150)$ in males $](P<0.0001)$.

\section{Discussion}

Epidemiological data on HAV infection are limited in the Islamic Republic of Iran and this was the first systematized population-based survey of immunity to HAV infections by age ( $1-25$ years) in urban and rural inhabitants in Sari/ Mazandaran. The overall prevalence of anti-HAV in those aged under 25 years in Sari was 38.9\%.

Only $13.8 \%$ of the inhabitants under 15 years old had immunity against hepatitis A. The seroprevalence of anti-HAV in individuals younger than 25 years in 2007 was $38.9 \%$, which is considerably lower than that of a corresponding study in 1997 in this city (90.6\% in those aged $>5$ years old) [4]. This finding implies that hepatitis A is no longer hyperendemic in Sari. This has led to a shift in hepatitis A patients in Sari towards older age groups, in which clinical illness is likely to be more frequent and severe $[3,5,6]$.

A seroprevalence study in 2005 in Zabol (a city in the south-east of the Islamic Republic of Iran) revealed a 100\% seropositive rate in people aged 15-19 years old [7]. This means that Zabol is a hyperendemic region of hepatitis A. Other studies carried out in Shiraz and Tehran (the 2 largest cities in the country), where the seroprevalence of HAV in 1997 was $33 \%-37 \%$ in the age group $<5$ years and $68 \%-76 \%$ in age group 10-14 years, confirm our results [8]. Results of a recent study in Tehran in 2004 found a lower rate of HAV seroprevalence $(22.5 \%$ in the

\begin{tabular}{|c|c|c|c|c|}
\hline \multirow[t]{2}{*}{ Variable } & \multicolumn{3}{|c|}{ HAV positive } & \multirow[t]{2}{*}{$P$-value } \\
\hline & No. & $\%$ & OR $(95 \% \mathrm{Cl})$ & \\
\hline \multicolumn{5}{|l|}{ Age (years) } \\
\hline $1-5(n=192)$ & 18 & 8.9 & 1 & \multirow{3}{*}{0.001} \\
\hline $5-15(n=330)$ & 54 & 15.8 & $1.89(1.07-3.30)$ & \\
\hline $15-25(n=512)$ & 330 & 64.3 & $17.50(10.4-29.4)$ & \\
\hline \multicolumn{5}{|l|}{ Location } \\
\hline Urban $(n=620)$ & 185 & 29.8 & $1.39(1.06-1.83)$ & \multirow{2}{*}{0.018} \\
\hline Rural $(n=414)$ & 217 & 52.4 & 1 & \\
\hline \multicolumn{5}{|l|}{ Sex } \\
\hline Male $(n=452)$ & 134 & 29.6 & $2.02(1.50-2.60)$ & \multirow{2}{*}{0.001} \\
\hline Female $(n=582)$ & 268 & 46.0 & 1 & \\
\hline
\end{tabular}

$O R=$ odds ratio $; C I=$ confidence interval . 
age group 10-15 years) [9]. Results of a seroprevalence study among Iranian soldiers in 2006 revealed that $97.6 \%$ of subjects had anti-HAV antibody [10]. The authors believed that there was no need for preventive methods in the military setting at that time.

It seems therefore that hepatitis A is still endemic in many parts of our country. The seroprevalence rate is dependent on different factors such as individual and social health standards and environmental factor and vaccine schedules.

Many recent reports indicate a global change in seroepidemiological patterns of HAV infection [11-14]. The seronegativity of HAV among children aged 4-14 years in Jeddah, Saudi Arabia in 2004 was $70.5 \%$ [11]. In Delhi in India, the seroprevalence in people younger than 35 years old was similar to that of the more developed European countries [12]. In Thailand, the prevalence of anti-HAV was $1.95 \%$ in Bangkok and $12.7 \%$ in other provinces in people younger than 25 years [13]. In Japan the prevalence of anti-HAV in 2003 was $12.2 \%$ and it was rarely detected in those aged $0-44$ years [14]. In many Western European countries [15], following improvements of the standard of living in the industrialized world, age-specific HAV seroprevalence in the general population has decreased steadily and the risk of acquiring HAV infection is high for travellers to high HAV endemic areas in developing countries. Typically, improved sanitation facilities are provided in metropolitan regions first; thus, exposure to HAV remains more common in rural regions and small cities where it principally affects the youngest inhabitants. This study in the north of our country where the people have a high socioeconomic level suggested that Sari, like most large cities in the Islamic Republic of Iran, is moving toward an intermediate epidemic state for HAV.
The seroprevalence of HAV in our study was lowest in the first decade of life and the highest in the age group over 15 years old. The present study showed that rural regions had the highest seroprevalence of HAV infection, with an estimated rate of $47.1 \%$ compared with $33.8 \%$ in urban areas. These results suggest that, as shown in other studies, exposure to HAV in Sari was probably earlier in rural areas than in urban areas [16-18].

Regarding sociodemographic variables, our findings are consistent with several previous studies showing a clear inverse correlation between exposure to HAV and socioeconomic level [1921]. It is well known that HAV infection is strongly correlated with poverty and inadequate sanitation. Increasing household income, education, water quality and quantity, sanitation and hygiene lead to decreased HAV prevalence. Indeed, the prevalence of HAV infection could even be used as an index of the level of development in a given country.

HAV is a health problem in countries where the seroepidemiology is changing from hyperendemicity to intermediate endemicity $[22,23]$. In these cases there are different patterns, with pockets of low prevalence; studies have found a decline of anti-HAV prevalence among urban children, which leads to a risk of outbreaks of HAV infection among this population [21-23]. The infection is predicted to shift to adulthood with more severe clinical manifestations in the future. Then it is important to determine the pattern of HAV infection in each community in order to optimize vaccination strategies by identifying high-risk populations for vaccination.

This study showed that HAV infection had intermediate endemicity in Sari. So we have a large group of susceptible people who are at risk for acquisition of acute infection. In recent years there have been several case reports of fulminant hepatitis in 18-25-year-olds in our area and also several reports of acute HAV infection outbreak among families. In our sample $47.5 \%$ of $15-25$-year-olds in urban areas had HAV susceptibility, which means that preventive methods such as anti-HAV Ig or HAV vaccination need to be considered.

The existence of some hyperendemic areas in our country such as in Zabol [7] suggests that there is a great need to establish a preventive strategy against hepatitis A in our area, especially for travellers to endemic areas. Similar seroprevalence studies need be conducted to detect shifts in HAV endemicity in Islamic Republic of Iran in order to plan vaccination strategies.

\section{Conclusion}

In conclusion, the decreasing HAV seroconversion observed in our study suggests Sari is no longer classified among areas of high endemicity. Inhabitants appear to have acquired a lifelong immunity as a result of natural infection during childhood. These findings support the implementation of vaccination in high-risk groups. The surveillance of the epidemiological trend of HAV infection will contribute to the definition of endemicity in Islamic Republic of Iran for implementing preventive measures and for controlling the disease.

\section{Acknowledgements}

This work was supported by Mazandaran University of Medical Sciences. We would like to thank Dr Noorani and Dr Farahanian for providing serum specimens, Mr Mirabi who performed the enzyme immunoassay and Ms Masoomian and everyone who assisted with the study. 


\section{References}

1. Fiore AE. Hepatitis A transmitted by food. Clinical Infectious Diseases, 2004, 38:705-715.

2. Hepatitis A. Geneva, World Health Organization, 2000 (WHO/ CDS/CSR/EDC/2000-7).

3. Jacobsen $\mathrm{KH}$, Koopman JS. The effects of socioeconomic development on worldwide hepatitis A virus seroprevalence patterns. International Journal of Epidemiology, 2005 34:600-609.

4. Saffar MJ, Hemmatabadi M. Prevalence of hepatitis A in 1-15 years old children in Sari 1996-97.Journal of Mazandaran University of Medical Science, 1999, 9(22-23):1-4.

5. Hadler SC.. Global impact of hepatitis A virus infection changing patterns. In: Hollinge FB, Lemon SM, Margolis H, eds. Viral hepatitis and liver diseases. Baltimore, Maryland, Williams and Wilkins, 1991:14-20.

6. Koff RS. Clinical manifestations and diagnosis of hepatitis A virus infection. Vaccine, 1992, 10:S15-S17.

7. Salehi M, Sanei M. Hepatitis A seroepidemiology in under 30 years old population. Journal of Guilan University of Medical Sciences, 2005, 10:37-38.

8. Alborzi P. Age group who need gamma glubulin in contact with hepatitis $A$. Proceedings of the 7th Iranian Congress on Infection Disease and Tropical Medicine, Babolsar, Islamic Republic of Iran, 6-8 October, 1998.

9. Mehr AJ et al. Age specific seroprevalence of hepatitis A infection among children visited in pediatric hospitals of Tehran, Iran. European Journal of Epidemiology, 2004, 19:275-278.

10. Ghorbani G, Alavian SM, Assari S. Seroepidemiology of hepatitis A in Iranian soldiers in 2006: do they need vaccination? Hepatitis Monthly, 2007, 7:7-9.

11. Jaber SM. Prevalence of anti-hepatitis B and anti-hepatitis A antibodies among school aged children in Western Saudi Arabia. Saudi Medical Journal, 2006, 27:1515-1522.

12. Das K et al. The changing epidemiological pattern of hepatitis A in an urban population of India: emergence of a trend similar to the European countries. European Journal of Epidemiology, 2000, 16:507-510.

13. Ratanasuwan W et al. Serological survey of viral hepatitis A, B, and $\mathrm{C}$ at Thai Central Region and Bangkok: a population base study. Southeast Asian Journal of Tropical Medicine and Public Health, 2004, 35:416-420.

14. Kiyohara T et al. Shifting seroepidemilogy of Hepatitis A in Japan, 1973-2003. Microbiology and Immunology, 2007, 51:185-191.

15. Jacobsen $\mathrm{KH}$, Koopman JS. The effect of scocioeconomic development on world wide hepatitis A seroprevalence pattern. International Journal of Epidemiology, 2005, 34:600-609.

16. Raharimanga $V$ et al. Age-specific seroprevalence of hepatitis A in Antananarivo (Madagascar). BMC Infectious Diseases, 2008, 8:78.

17. Vancelik S, Guraksin A, Alp H. Hepatitis A seroepidemiology in Eastern Turkey. East African Medical Journal, 2006, 83:86-90.

18. Mall ML et al. Seroepidemiology of hepatitis A infection in India: changing pattern. Indian Journal of Gastroenterology, 2002, 21:40-41.

19. Zago-Gomes MP, Stantolin GC, Perazzio S. Prevalence of antihepatitis A antibodies in children of different socioeconomic conditions in Vila Velha. Revista da Sociedade Brasileira de Medicina Tropical, 2005, 38:285-289.

20. Tanaka J. Hepatitis A: shifting epidemiology in Latin America. Vaccine, 2000, 18:S57-S60.

21. Haysam T. Hepatitis A shifting epidemiology in Middle East and Africa. Vaccine, 2000, 18:S65-S67

22. Mphahlele J. Epidemiology of hepatitis A virus infection in South Africa. Proceedings of the First Global Hepatitis A Meeting, Miami, Untied States of America, 30 November-1 December, 2007.

23. Letaief A et al. Age-specific seroprevalence of hepatitis a among school children in central Tunisia. American Journal of Tropical Medicine and Hygiene, 2005, 73:40-43. 